\title{
The relationship between art as a therapeutic resource and the quality of life in patients with schizophrenia
}

\begin{abstract}
The general aim of this study was to check the relationship between an Artistic Ceramics Workshop (ACW) and Quality of Life (QOL) of people with clinical diagnosis of schizophrenia of both genders and check if the obtained results were stable in time. Therefore was constituted a convenience sample $(n=9)$ in SocioOccupational Centers and the participants were medicated and in a stabilized phase of the disease. The ACW was implemented over five months, with a weekly frequency of two sessions of 90 minutes each and the evaluation instrument (WHOQOL-BREF) administered at three different observation moments (before, after the intervention and 27 days after the intervention). Considering the obtained results, the ACW produced significant improvement in the QOL of participants and it was also verified that the obtained results were not stable in time, and with the female gender the intervention was more efficient in terms of the general perception of QOL and general perception of health. We can also conclude that the lack of motivation of the participants regarding interventions that use art as a therapeutic resource can influence its effectiveness.
\end{abstract}

Volume 3 Issue I - 2018

\author{
Victor Hugo Palma,' Luís Barriga, ${ }^{2}$ Sandra \\ Cruz, ${ }^{3}$ Ana Paula Gama ${ }^{4}$ \\ 'Department of Psychology and Educational Sciences, \\ Universidade do Algarve, Portugal \\ ${ }^{2}$ Superior Institute Dom Afonso III, University in Loulé, Portugal \\ ${ }^{3}$ Superior School of Management, Hospitality and Turism, \\ Portugal \\ ${ }^{4}$ Department of Clinical and Experimental Psychology, Portugal
}

Correspondence: Victor Hugo Palma, Department of Psychology and Educational Sciences, Universidade do Algarve, Portugal,Tel 35I 962767239, Email victorhugopalma@sapo.pt

Received: November 16, 2017| Published: February 07, 2018

Keywords: schizophrenia, artistic ceramics, workshop, quality of life

\section{Introduction}

Schizophrenia is one of the most serious and disabling mental illness that affects about $1 \%$ of the Portuguese population ${ }^{1,2}$ being its central feature the loss of contact with reality., ${ }^{1,3}$ This mental illness can install itself in an insidious or acute form ${ }^{1,4}$ the period of greatest risk lies between late adolescence and early adulthood ${ }^{1,3,4}$ in females can occur later ${ }^{1,4}$ however even if the age factor cannot be regarded as decisive in the exclusion of the diagnosis ${ }^{1,3}$ it rarely occurs before the age of ten or after 50 years of age. ${ }^{3}$

At present it is consensual that psychosocial interventions should be included to increase the effectiveness of the treatment of people with schizophrenia. ${ }^{1,3,5}$ The activities developed in the Therapeutic Workshop (TW) is one of those cases, and can contribute to the change of the routines of the person with mental illness ${ }^{6}$ remove them from a passive role to an active one ${ }^{7}$ and give them the opportunity to see that they too, have the capacity to perform tasks with success. ${ }^{8}$ The TW also perform an integrative function as they are developed in group ${ }^{2,6}$ which may contribute to establish bonds beyond the nuclear family. ${ }^{6}$ The TW also provide people with schizophrenia access to the community culture, and, as relations with the environment are rebuilt $t^{6,9}$ it can act to prevent the social exclusion, that the vast majority of them is subject to. ${ }^{6}$ Clay modeling is an activity used with regularity in $\mathrm{TW}^{10}$ since it does not require very elaborate skills, its independent of the degree of schooling ${ }^{11}$ also, the great plasticity of this material, facilitates manipulation ${ }^{11,12}$ and, being the sensorial experiences of extreme importance for the human being ${ }^{13}$ this is a means par excellence to provide that experience..$^{11}$ In addition, the benefits to motor skills, as both hands are used ${ }^{14}$ the three-dimensionality of the pieces produced ${ }^{11,12}$ the possibility to create utilitarian objects with an aesthetic component ${ }^{15}$ and the fact that the pieces in clay modeling allow a direct contact with the material with which we work ${ }^{11,12}$ are factors that enhance this activity when compared to others. ${ }^{15}$

\section{Method}

The general aim of the present study was to analyze the relationship between the ACW and the QOL of people with clinical diagnosis of schizophrenia of both genders and if the data obtained remained stable in time.

\section{Participants}

This study used a convenience sample, composed of nine subjects, male $(n=6 ; 66.7 \%)$ and female $(n=3 ; 33.3 \%)$, aged between 19 and 60 years $($ Mean=34.11; SD=13.07) with a clinical diagnosis of schizophrenia. These patients were given support in a SocioOccupational Center were accompanied in ambulatory regimen by their psychiatrists, medicated and in a stabilized phase of the disease

\section{Material}

The instrument used to assess the QOL was the World Health Organization Quality of Life-BREF (WHOQOL-BREF), adapted to Portugal by ${ }^{15}$ This instrument consists of 26 items, two of which related to a general factor (General Facet of QOL) composed of two items that assess the general perception of QOL and the general perception of health and the remaining 24 items assess QDV from four domains: Physical, Psychological, Social relationships and environmental. This is a Likert type scale with five response alternatives, where the participant must indicate the option that best corresponds to his situation, over the last two weeks. The high scores represent better QOL. ${ }^{15}$ The analysis of the obtained data was made using the program IBM SPSS Statistics 20 for Windows. 


\section{Results}

The sample was initially composed of 12 people with schizophrenia, although three of them only attended ACW two sessions $(n=1)$ and four sessions $(\mathrm{n}=2)$. Thus, there was an "experimental mortality" $(\mathrm{n}=3)$ (Table 1).

Table I Friedman test for all scales and subscales under study

\begin{tabular}{|c|c|c|c|c|c|c|c|c|c|}
\hline & \multicolumn{2}{|c|}{ I'Moment } & \multicolumn{2}{|c|}{$2^{\circ}$ Moment } & \multicolumn{2}{|c|}{$3^{\circ}$ Moment } & \multirow[t]{2}{*}{$\mathbf{X}^{2}$} & \multirow[t]{2}{*}{ df } & \multirow[t]{2}{*}{$\mathbf{p}$} \\
\hline & Mean & SD & Mean & SD & Mean & SD & & & \\
\hline WHOQOL-bref & 75,625 & 15,136 & 98,777 & 12,346 & 90,444 & 11,023 & 16,000 & 2 & 0,000 \\
\hline Domain I & 18,625 & 4,983 & 24,444 & 3,609 & 22,777 & 3,734 & 12,286 & 2 & 0,002 \\
\hline Domain 2 & 16,888 & 3,257 & 21,777 & 2,587 & 19,000 & 2,291 & 17,543 & 2 & 0,000 \\
\hline Domain 3 & 7,555 & 2,403 & 10,222 & 2,333 & 9,222 & 1,986 & 9,290 & 2 & 0,010 \\
\hline Domain 4 & 22,888 & 4,512 & 27,000 & 3,278 & 25,222 & 3,767 & 9,484 & 2 & 0,009 \\
\hline Overall & 10,666 & 3,605 & 15,333 & 2,828 & 14,222 & 2,333 & 16,710 & 2 & 0,000 \\
\hline
\end{tabular}

SD, standard deviation; $X^{2}$, Chi-square; df: degree of freedom; $p$, significance level for $\alpha \leq 0,05$.

\section{Discussion}

The results obtained refer to participants whose attendance was high (more than $75 \%$ of ACW sessions) and were present at the three moments of observation and, therefore, it can be assumed that they were motivated for this type of intervention, also taking into account the verbalizations produced (eg, "I can also do it", "I thought it was more difficult", "I like it a lot", "I can do things that are the same as stores"). Considering the early abandonment of the three participants and their verbalizations to justify it (eg, "I don't like this", "I prefer the other activities"), it can be explained by the lack of motivation regarding this type of activity, ${ }^{16,17}$ when they report that not all patients are motivated for interventions that use creative activities as a therapeutic resource. Regarding the data obtained, referring to the literary qualifications of the participants, it was verified that they are in agreement with the literature review, which states that most of these patients have a low level of schooling, ${ }^{18}$ low percentages of marriages ${ }^{18,19}$ low rates of employment ${ }^{18}$ and non-recognition of the disease itself, which occurs in a large number of cases. ${ }^{1,3,19}$

In the WHOQOL-Brief scale, the values obtained showed a rise in the first (Mean=75.6250; $\mathrm{SD}=15.1388$ ) for the second observation time (Mean=98.7778; $\mathrm{SD}=12.34684$ ) and a decrease in second for the third observation time (Mean=90.4444; $\mathrm{SD}=11.02396$ ), but it should be noted that the values of the latter remained higher when compared to the first moment of observation. The results suggest that the intervention produced improvements in the QOL of the participants, but they were not stable over time, and this may be in agreement with $^{1}$ the report that schizophrenia is in most cases a chronic disease, therefore, psychosocial interventions must accompany its evolution with the appropriate adaptations to the moment, since skills develop but also undergo transformations over time.

The fact that the intervention in question has produced benefits in the QOL of the participants is in accordance with ${ }^{2}$ and that, through the work developed in TWs and the yours valorization, people with mental illness can improve their QOL. Considering the four domains of the "WHOQOL-BREF" and the improvements produced by the intervention in all of them, corroborating the one mentioned by the consulted authors, we emphasize that clay modeling is a means par excellence for experiencing diverse sensorial experiences ${ }^{11}$ may contribute to the development of motor skills ${ }^{14}$ may promote the reduction of anxiety and aggressiveness ${ }^{7,11}$ the art used as a therapeutic resource can provide people with mental illness with the expression of thinking and emotions, through non-verbal communication ${ }^{7,11,14}$ the activities developed in TWs may have an integrative function, contributing to stimulate interpersonal relationships ${ }^{2,14}$ and allow a reunion between the person with mental illness and a community culture, which may contribute to the reconstruction of relations with the environment. ${ }^{6,9}$

\section{Conclusion}

We conclude that the ACW produced improvements on the global QOL level, although the results obtained were not stable over time, however, it should be noted that the benefits extended beyond the end of the intervention, the results obtained in the third moment of observation, although lower than the second, remained higher when compared to those recorded before the intervention. We also concluded that the intervention was more effective in the female gender, regarding the general perception of QOL and the general perception of health. We also conclude that the lack of motivation of the participants, regarding interventions that use art as a therapeutic resource, can influence its effectiveness.

\section{Acknowledgements}

None.

\section{Conflict of interest}

The author declares no conflict of interest.

\section{References}

1. Afonso P. Esquizofrenia: Para além dos mitos, descobrir a doença. Cascais, Portugal: Principia; 2010.

2. Cordo M. Reabilitação de pessoas com doença mental: Portugal. 2003.

3. Vaz SA, Pereira M, Leitão J. Qualidade de vida em doentes esquizofrénicos. In: M Canavarro, Vaz SA, editors. Qualidade de vida e saúde: Uma abordagem na prespectiva da organização mundial de saúde. 2010. p. 271-282.

4. American Psychiatric Association. Diagnostic and statistical manual of mental disorder. 4th ed. DSM-IV-TR. Washington, USA: Climepsi editores; 2006. 
5. Kern R, GlynnS, William P, et al. Psychosocial treatments to promote functional recovery in schizophrenia. Schizophrenia Bulletin. 2009;35(2):347-361

6. Brunello M, Castro E, Lima E. Atividades humanas e terapia ocupacional. In: Bartalotti, M Carlo, editors. Terapia ocupacional no brasil: Fundamentos e perspectivas. São Paulo, Brazil; 2001. p. 41-59.

7. Rocha R. Enfermagem em saúde mental. 2nd ed. Brazil: Editora Senac Nacional; 2005

8. Shirakawa I. Aspectos gerais do manejo do tratamento de pacientes com esquizofrenia. Revista Brasileira de Psiquiatria. 2000;22(1):56-58.

9. Guerra A. Oficinas em saúde mental: Percurso de uma história fundamentos de uma prática. In: C Costa, A Figueiredo, editors. Oficinas terapêuticas em saúde mental: Sujeito, produção e cidadania. Rio de Janeir, Brazil: Contra Capa Livraria; 2004. p. 23-58.

10. Galletti M. Oficina em saúde mental: Instrumento terapêutico ou intercessor clínico? Goiânia: Editora da Universidade Católica de Goiás; 2004

11. Chiesa R. O diálogo com o barro: O encontro com o criativo. São Paulo, Brazil: Casa do Psicólogo; 2004.

12. Philippini A. Linguagens, materiais expressivos em arteterapia: Uso, indicações e propriedades. Rio de Janeiro, Brazil: Wak Editora; 2009.
13. Couvreur C. A qualidade de vida: Arte para viver no século XXI. Loures, Portugal: Lusociência; 2001.

14. Sanz AB, Del RM. La creación artística como tratamiento de la esquizofrenia: Una aproximación metodológica. Archivos de Psiquiatría. 2010;73(2):1-18.

15. Vaz SA, Canavarro $M$, Simões $M$, et al. Estudos psicométricos do instrumento de avaliação da qualidade de vida da organização mundial de saúde (whoqol-bref) para português de portugal. Psiquiatria Clínica. 2006;27(1):41-49.

16. Crawford M, Killaspy H, Barnes T, et al. Group art therapy as an adjunctive treatment for people with schizophrenia: Multicentre pragmatic randomised trial. British Medical Journal. 2012;344:e846.

17. Palma VH, Barriga L, Cruz S, et al. Modelando a sintomatologia psicótica: A arte como recurso terapêutico em saúde mental. Psicologia Saúde \& Doenças. 2017;18(1):20-29.

18. Marques TJ. Neurocognição, cognição social e funcionamento social na esquizofrenia. Saúde Mental. 2007;9(6):7-9.

19. Louzã NM, Elkis H. Psiquiatria básica. 2nd ed., Porto Alegre, Brazil: Artmed Editora; 2007 